\title{
An Estimation Method for Real-Time Thermal Capacity of Traction Transformers under Unbalanced Loads
}

DOI:

10.1109/TIE.2020.3036252

Document Version

Accepted author manuscript

Link to publication record in Manchester Research Explorer

\section{Citation for published version (APA):}

Zhou, L., Wang, L., Zhang, X., Liu, Q., Guo, L., \& Wang, D. (2020). An Estimation Method for Real-Time Thermal Capacity of Traction Transformers under Unbalanced Loads. IEEE Transactions on Industrial Electronics, 1-1. https://doi.org/10.1109/TIE.2020.3036252

\section{Published in:}

IEEE Transactions on Industrial Electronics

\section{Citing this paper}

Please note that where the full-text provided on Manchester Research Explorer is the Author Accepted Manuscript or Proof version this may differ from the final Published version. If citing, it is advised that you check and use the publisher's definitive version.

\section{General rights}

Copyright and moral rights for the publications made accessible in the Research Explorer are retained by the authors and/or other copyright owners and it is a condition of accessing publications that users recognise and abide by the legal requirements associated with these rights.

\section{Takedown policy}

If you believe that this document breaches copyright please refer to the University of Manchester's Takedown Procedures [http://man.ac.uk/04Y6Bo] or contact uml.scholarlycommunications@manchester.ac.uk providing relevant details, so we can investigate your claim.

\section{OPEN ACCESS}




\title{
An Estimation Method for Real-Time Thermal Capacity of Traction Transformers under Unbalanced Loads
}

\author{
Lijun Zhou, IEEE Member, Lujia Wang, IEEE Member, Xiang Zhang, IEEE Member, \\ Qiang Liu, IEEE Senior Member, Lei Guo, Dongyang Wang, IEEE Member
}

\begin{abstract}
${ }^{1}$ Abstract-Real-time thermal capacity estimation is not only part of prognostics and health management (PHM) but also determines the dynamic loading capability of the traction transformer. The hot-spot temperature is the vital parameter for real-time thermal capacity estimation. In high-speed railway, the unbalanced loads of the two phases of the traction transformer cause unbalanced winding losses and therefore affect the top-oil temperature and further influence the hot-spot temperature in each phase. In order to explore the dynamic thermal performance of the transformer under unbalanced load (current), a thermal model for calculating the hot-spot temperature was proposed incorporating thermal interaction between two power supply phases. This model treats the winding loss of each phase independently, considering the temperature dependence of winding ohmic losses and eddy current losses. A thermal circuit topology was presented with independent phase windings sharing the same top-oil temperature, where an improved heat transfer correlation was used to account for the nonlinear thermal convection. The proposed model was verified by the factory temperature rise tests and field operation data for the same batch of transformers.
\end{abstract}

Index Terms-High-speed railway; Oil-immersed transformer; Loading capability; Hot-spot temperature; Unbalanced load.

\section{NOMENCLATURE}

$A \quad$ Area $\left(m^{2}\right)$.

$C_{t h} \quad$ Thermal capacity $(\mathrm{J} / \mathrm{kg})$.

$c_{p} \quad$ Specific heat $(\mathrm{J} / \mathrm{K} \cdot \mathrm{kg})$.

$G r \quad$ Grashof number.

$g \quad$ The acceleration of gravity $\left(9.8 \mathrm{~m} / \mathrm{s}^{2}\right)$.

Manuscript received January 28, 2020; revised August 28, 2020; accepted October 22, 2020. This work was supported in part by the National Nature Science Foundation of China under Grant U1834203, in part by the Sichuan Science and Technology Program under Grant 2020JDTD0009. (Corresponding authors: Lujia Wang.)

Lijun Zhou, Lei Guo, and Dongyang Wang are with the School of Electrical Engineering, Southwest Jiaotong University, Chengdu 611756, China (e-mail: ljzhou10@163.com; jiulingthebest@163.com; guolei_mail@163.cn).

Lujia Wang is with the School of Electrical and Power Engineering, China University of Mining and Technology, Xuzhou 221116, China (e-mail: lujia.wang@cumt.edu.cn).

Xiang Zhang and Qiang Liu are with the Department of Electrical and Electronics Engineering, The University of Manchester, Manchester M13 9PL, UK (e-mail: qiang.liu@manchester.ac.uk). $h$

I

$K^{2}$

$k$

$L$

$\mathrm{Nu}$

$n$

$\operatorname{Pr}$

$P$

$p$

$q$

$R$

$R_{\text {th }}$

$R g$

$r$

$S$

$\Delta \theta_{\text {oil }}$

$\Delta \theta_{h s}$

\section{Greek:}

$\beta \quad$ The coefficient of thermal expansion $(1 / K)$.

$\rho \quad$ The density $\left(\mathrm{kg} / \mathrm{m}^{3}\right)$.

$\theta \quad$ Temperature $(K)$.

$\tau_{\text {oil }} \quad$ Top-oil time constant (min).

$\tau_{w} \quad$ Winding time constant ( $\mathrm{min}$ ).

$\mu \quad$ Oil viscosity $(\mathrm{kg} / \mathrm{m} \cdot \mathrm{s})$.

\section{Abbreviation Subscripts:}

$\alpha, \beta \quad$ Secondary phases of traction transformer.

amb Ambient.

$A, B, C$ Three-phase power source connecting to the primary windings (high-voltage) of $\mathrm{V} / \mathrm{x}$ transformer.

dc Ohmic loss.

eddy Eddy loss.

$F \quad$ Feeder lines in TPSS.

$h s \quad$ Hot spot.

pu Per unit value.

rated Rated.

ref Reference spot for oil temperature.

$T \quad$ Contact lines (catenary) in TPSS.

th Thermal. 


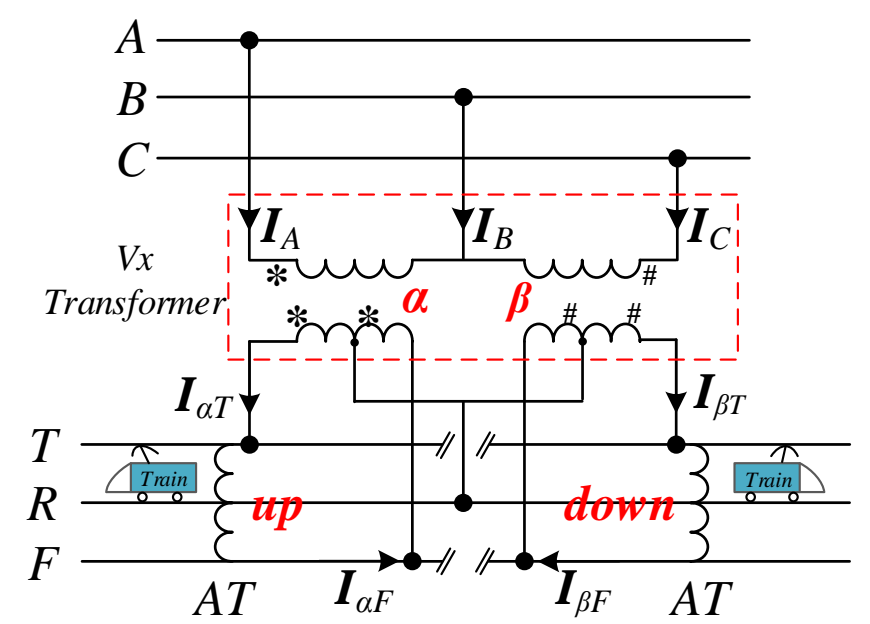

Fig. 1. Schematic diagram of TPSS.

\section{INTRODUCTION}

Power transformers are critical industry assets in both power systems and electrified railways. Condition monitoring and maintenance planning of transformers are crucial because it is strongly related to the safety and stability [1], [2], [3]. Prognostics and health management (PHM) strategies have emerged as effective solutions to manage power transformers, where real-time thermal capacity estimation (also called as thermal management or thermal rating) is an important part of PHM. Besides, the transformer loading capability should be assessed by real-time thermal capacity estimation, thus transformers can be safely operated under changing load and environmental conditions [4], [5]. Among the monitored parameters of real-time thermal capacity estimation, the maximum winding temperature is the vital one.

The hot-spot temperature (HST, sometimes also called as the hottest spot temperature) is one of the key factors that limit the loading capacity of transformers and determine the lifetime of the transformer insulation [6], [7], [8]. Developing dynamic thermal models is an effective way to calculate HST and therefore estimate the loading capability [9]. In general, the HST differences among different phases are omitted because of symmetrical loading. However, in some special occasions, transformers bear unbalanced loads (currents). For example, in high-speed railway (HSR) traction power supply systems (TPSS), there exists obvious unbalanced loads in the transformer due to different catering demands by running electric multiple units (EMUs) and special winding connections of the transformer [10].

A typical topology of TPSS is illustrated in Fig. 1. This TPSS includes traction transformers, several autotransformer substations (ATSs), catenary network and running trains. The traction transformer ( $\mathrm{V} / \mathrm{x}$ connection type) steps three-phase $220 \mathrm{kV}$ down to two sets of single-phase $2 \times 27.5 \mathrm{kV}$ feeders for $\alpha, \beta$ supply phases separated by neutral sections [10]. In addition, most HSR lines have been adopted as two $27.5-\mathrm{kV}$ autotransformer (AT) fed system as a power-supply for EMUs. Furthermore, the $\alpha$ phase take the responsibility of power supply for the up-track and $\beta$ phase for the down-track, with different loads in most times. The unbalanced loads cause unbalanced winding losses and therefore affect the top-oil temperature and further influence the HST in each phase.

The electrical-thermal analogy is an effective method for heat transfer analysis. To further develop the thermal circuit, research efforts have been made to the structure of the thermal circuit model and its physical interpretation, and particularly for the nonlinear convective heat transfer and nonlinear thermal resistance as was proposed in [9], [11], [12]. Considering a variety of transformer operating environments, more detailed thermal circuit models were proposed to address specific issues as in [13], [14], [15], [16], [17]. However, after building thermal circuit models, a fewer design-dependent variables are involved in the model. The more specific the thermal circuit structure is, the more design-dependent variables and heat transfer correlations will be required. How to choose appropriate correlations and their coefficients are crucial for the model accuracy. Furthermore, in simplified thermal circuit [9], during the derivation process to differential equations, most heat transfer correlations can be boiled down to a formula containing the nameplate information and a fewer empirical constants.

As for the unbalanced load scenario, voltage imbalance is not uncommon. Atabak Najafi explored the thermal dynamic and thermal aging rate under three-phase unbalanced-voltage scenarios [17]. The article presented an extremely detailed thermal circuit structure, considering the thermal resistance between phases. This detailed circuit requires numerous detailed design parameters and a large number of correlation equations. The result showed that the voltage has minor influence on the thermal behavior. In contrast, the thermal effect of unbalanced load current carried by the traction transformer is more pronounced. To investigate the thermal effect of unbalanced loads (currents), two questions need to be addressed properly: 1) how to deal with the heat transfer between the two phases; 2) how to select the correlation equations and their coefficients to account for nonlinear thermal resistance in the model.

In this paper, in order to fulfill the real-time thermal capacity estimation for traction transformers in high-speed railways, a thermal model for calculating the HST was proposed. The model accounts for thermal interaction between the two power supply phases, i.e., $\alpha$ and $\beta$ supply phases and treats the winding losses independently, considering the temperature dependence of winding ohmic losses and eddy current losses. A thermal circuit topology was presented with each phase separately represented but sharing the same top-oil temperature. The determination of the top-oil temperature considers the nonlinear convective heat transfer with appropriate heat transfer correlations selected. The proposed model was verified by the factory temperature rise tests and field operation data for the same batch of transformers.

\section{UnBalanced Electrical Power Loss Relationship}

Unbalanced loads bring different power losses in $\alpha, \beta$ phases of the traction transformer. The current transform matrix 
between local power grid and feeders, catenaries is shown as:

$$
\left[\begin{array}{c}
f_{A}^{\&} \\
f_{B}^{\&} \\
\mu_{C}^{\&}
\end{array}\right]=\frac{1}{n}\left[\begin{array}{cccc}
1 & 1 & 0 & 0 \\
-1 & -1 & -1 & -1 \\
0 & 0 & 1 & 1
\end{array}\right] \times\left[\begin{array}{c}
P_{\alpha T}^{\&} \\
\mathcal{L}_{\alpha F}^{\&} \\
\mathcal{P}_{\beta T}^{\&} \\
\mu_{\beta F}^{\&}
\end{array}\right]
$$

Ideally, the valid values of $\alpha, \beta$ phases can be depicted as,

$$
\left[\begin{array}{c}
I_{A} \\
I_{C}
\end{array}\right]=\frac{1}{n}\left[\begin{array}{c}
I_{\alpha T}+I_{\alpha F} \\
I_{\beta T}+I_{\beta F}
\end{array}\right]
$$

Next, $\alpha$ phase will be investigated and modelled as an example. In the temperature rise test or an ideal condition, the catenary current $I_{\alpha T}$ equals the feeder current $I_{\alpha F}$, which can be set as rated condition. So, the rated current relationship was presented as:

$$
I_{A-\text { rated }}: I_{\alpha F-\text { rated }}: I_{\alpha T \text {-rated }}=2: n: n
$$

The rated ohmic loss relationship can be shown as,

$$
\begin{aligned}
P_{A-d c-\text { rated }}: & P_{\alpha F-d c-\text { rated }}: P_{\alpha T-d c-\text { rated }}= \\
& 2^{2} \cdot R_{A}: n^{2} \cdot R_{\alpha F}: n^{2} \cdot R_{\alpha T}
\end{aligned}
$$

Under any catenary current $I_{\alpha T}$ and any feeder current $I_{\alpha F}$, the ohmic loss in different windings of $\alpha$ phase can be described as:

$$
\begin{gathered}
{\left[\begin{array}{c}
P_{A-d c} \\
P_{\alpha F-d c} \\
P_{\alpha T-d c}
\end{array}\right]=\frac{P_{\alpha-d c-\text { rated }}}{n^{2} I_{A-\text { rated }}^{2}\left[4 R_{A}+n^{2}\left(R_{\alpha F}+R_{\alpha T}\right)\right]} \times} \\
{\left[\begin{array}{ccc}
\left(I_{\alpha F}+I_{\alpha T}\right)^{2} & 0 & 0 \\
0 & 4 I_{\alpha F}^{2} & 0 \\
0 & 0 & 4 I_{\alpha T}^{2}
\end{array}\right] \times\left[\begin{array}{c}
4 R_{A} \\
n^{2} R_{\alpha F} \\
n^{2} R_{\alpha T}
\end{array}\right]}
\end{gathered}
$$

So, the per unit value of winding ohmic loss in $\alpha$ phase is

$$
\begin{aligned}
P_{\alpha-d c-p u}= & \frac{P_{\alpha-d c}}{P_{\alpha-d c-\text { rated }}}=\frac{P_{A-d c}+P_{\alpha F-d c}+P_{\alpha T-d c}}{P_{\alpha-d c-\text { rated }}} \\
= & \frac{R_{A}\left(I_{\alpha F}+I_{\alpha T}\right)^{2}+n^{2}\left(I_{\alpha F}^{2} R_{\alpha F}+I_{\alpha T}^{2} R_{\alpha T}\right)}{n^{2} I_{A-\text { rated }}^{2} \times\left[R_{A}+\frac{n^{2}}{4}\left(R_{\alpha F}+R_{\alpha T}\right)\right]}
\end{aligned}
$$

If the catenary current $I_{\alpha T}$ equals the feeder current $I_{\alpha F}$, the per unit value of winding ohmic loss can be simplified as

$$
P_{\alpha-d c-p u}=\frac{\left(16 R_{A}+4 n^{2} R_{\alpha F}+4 n^{2} R_{\alpha T}\right) I_{\alpha T}^{2}}{n^{2} I_{A-\text { rated }}^{2} \times\left[4 R_{A}+n^{2}\left(R_{\alpha F}+R_{\alpha T}\right)\right]}
$$

The ratio of load loss $P_{\alpha}$ (increased by eddy current losses) to the ohmic loss can be determined as [18]:

$$
\frac{P_{\alpha}}{P_{\alpha-d c}}=\varphi+\frac{m^{2}-1}{3}
$$

where $m$ is the number of conductors perpendicular to the leakage duct and the value of $\varphi$ is:

$$
\varphi=2 \xi \frac{\sinh 2 \xi+\sin 2 \xi}{\cosh 2 \xi-\cos 2 \xi}
$$

where $\xi$ is the reduced conductor width, a dimensionless number defined as below:

$$
\xi=a \sqrt{\frac{N b}{l_{s}} \cdot R g \cdot \mu_{0} \sigma f}
$$

where $a$ is the conductor length perpendicular to the flux lines, $N$ is the number of conductors in the direction of the flux lines, $b$ is the conductor length in the direction of flux lines, $\mu_{0}$ is the permeability of vacuum, $f$ is the frequency in $H z, l_{s}$ is the length of leakage duct, $\sigma$ is the conductivity of the conductor and $R g$ is Rogowski coefficient defined as [18]:

$$
R g=1-\frac{a_{1}+a_{2}+\delta}{\pi l_{s}}\left(1-e^{-\frac{l_{s}}{a_{1}+a_{2}+\delta}}\right)
$$

where $a_{1}$ and $a_{2}$ are the length of two windings in the direction perpendicular to the stray flux lines and $\delta$ is the width of duct between windings. For a specific transformer, the terms $\varphi, \xi$ and $R g$ are fixed. Therefore, the ratio $P_{\alpha}$ to $P_{\alpha-d c}$ is independent of load current. With the following definition [19],

$$
\eta_{\alpha}=\frac{P_{\alpha-e d d y}}{P_{\alpha-d c}}=\frac{P_{\alpha-e d d y-\text { rated }}}{P_{\alpha-d c-\text { rated }}}
$$

Equation (8) can be rewritten as

$$
\frac{P_{\alpha}}{P_{\alpha-d c}}=\frac{P_{\alpha-d c}+P_{\alpha-e d d y}}{P_{\alpha-d c}}=1+\frac{P_{\alpha-e d d y}}{P_{\alpha-d c}}=1+\eta_{\alpha}
$$

Furthermore, considering the loss variation with temperature, the equivalent winding loss factor can be deduced as

$$
\begin{aligned}
K_{\alpha}^{2} & =\frac{P_{\alpha}}{P_{\alpha-\text { rated }}} \\
& =\frac{P_{\alpha-d c}+P_{\alpha-\text { eddy }}}{P_{\alpha-d c-\text { rated }}+P_{\alpha-\text { eddy-rated }}} \\
& =\frac{P_{\alpha-d c-p u} \cdot P_{\alpha-d c-\text { rated }} \cdot \kappa_{\alpha-d c}+\eta_{\alpha} \cdot P_{\alpha-d c} \cdot \kappa_{\alpha-\text { eddy }}}{P_{\alpha-d c-\text { rated }}+\eta_{\alpha} \cdot P_{\alpha-d c-\text { rated }}} \\
& =\frac{\kappa_{\alpha-d c}+\eta_{\alpha} \cdot \kappa_{\alpha-e d d y}}{1+\eta_{\alpha}} P_{\alpha-d c-p u}
\end{aligned}
$$

where the winding loss factor is related to the hot-spot temperature, so the temperature correction factors are:

$$
\begin{gathered}
\kappa_{\alpha-d c}=\frac{235+\theta_{\alpha h s}}{235+\theta_{\alpha h s-\text { rated }}} \\
\kappa_{\alpha-\text { eddy }}=\frac{235+\theta_{\alpha h s-\text { rated }}}{235+\theta_{\alpha h s}}
\end{gathered}
$$

Similarly, the $\beta$ phase equivalent winding loss factor is

$$
K_{\beta}^{2}=\frac{\kappa_{\beta-d c}+\eta_{\beta} \cdot \kappa_{\beta-e d d y}}{1+\eta_{\beta}} P_{\beta-d c-p u}
$$

\section{Thermal Circuit and Governing Differential EQUATIONS}

\section{A. Thermal Circuit Topology}

The thermal circuit model adopts electrical-thermal analogy and applies lumped capacitance and nonlinear thermal 


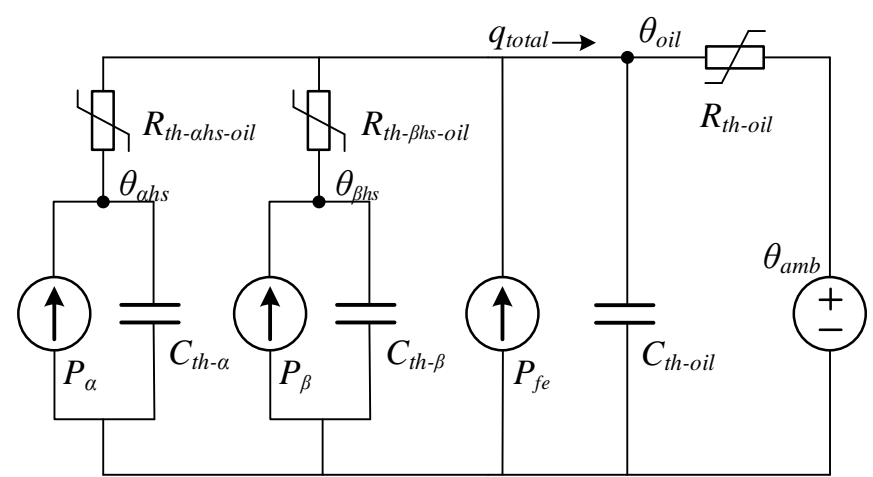

Fig. 2. Thermal circuit for $\mathrm{V} / \mathrm{x}$ connection traction transformer.

resistance. The model is based on fundamental heat transfer theory and has the advantage of convenience of calculation and clear physical interpretation. Different from the 2-segment model in [9], the proposed model has core loss and winding power loss sources represented for different phases because $\alpha, \beta$ phases have unbalanced loads. As shown in Fig. 2, the unbalanced thermal model is constructed considering the coupling relation in different windings, core and oil.

Based on Kirchhoff's Current Law (KCL), the governing differential equations can be derived as below,

$$
\begin{aligned}
& \left\{\begin{array}{l}
P_{\alpha}=\frac{\left(\theta_{\alpha h s}-\theta_{o i l}\right)}{R_{t h-\alpha h s-o i l}}+C_{t h-\alpha} \frac{d \theta_{\alpha h s}}{d t} \\
P_{\beta}=\frac{\left(\theta_{\beta h s}-\theta_{o i l}\right)}{R_{t h-\beta h s-o i l}}+C_{t h-\beta} \frac{d \theta_{\beta h s}}{d t} \\
P_{f e}=\frac{\left(\theta_{o i l}-\theta_{\text {amb }}\right)}{R_{t h-o i l}}+C_{t h-o i l} \frac{d \theta_{\text {oil }}}{d t}-
\end{array}\right.
\end{aligned}
$$

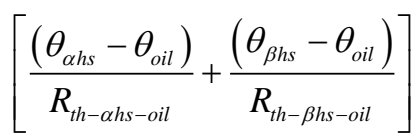

\section{B. Determination of Thermal Parameters}

Once the thermal circuit model is established, thermal parameters need to be determined. The methods for the thermal parameters determination can be divided into two types.

\section{1) Original Thermal Parameters Determination}

The electrical loss corresponds to the load current. Mass of each component and the material physical properties determine the heat capacity. However, it is hard to quantify the thermal resistances, which are determined by the geometric parameters, the material physical properties, the liquid flow conditions and the appropriate Nusselt number correlation equations [20], [21]. Both the heat transfer between the winding and adjacent oil (the average winding to average oil temperature gradient $g r$ ) and the heat transfer between the oil inside the radiator and the outside air (top-oil temperature rise over ambient temperature) are mainly convective heat transfer. Nonlinear thermal resistance is often used to describe these heat transfer processes, and its definition and derivation are as follows:

$$
\begin{gathered}
\frac{1}{R_{t h}}=h \cdot A \\
h=\frac{N u \cdot k\left(\theta_{r e f}\right)}{L} \\
N u=f(G r, P r) \\
\operatorname{Pr}\left(\theta_{r e f}\right)=\frac{\mu\left(\theta_{r e f}\right) \cdot c_{p}\left(\theta_{r e f}\right)}{k\left(\theta_{r e f}\right)} \\
\operatorname{Gr}\left(\theta_{r e f}\right)=L^{3} \cdot \frac{g \cdot \beta \cdot \rho^{2}\left(\theta_{r e f}\right) \cdot \Delta \theta}{\mu^{2}\left(\theta_{r e f}\right)}
\end{gathered}
$$

It can be seen that the selection of correlation equation (21) for the Nusselt number dominates the determination of the nonlinear resistances. For a vertical plate or a vertical cylinder with a small radius of curvature, the correlation was given in [22]. For ONAN oil-immersed transformers, the correlation presented by [22] is suitable for describing convective heat transfer between windings and oil, and radiator and air, irrespective of laminar or turbulent flow regime.

However, in the vertical oil duct, the heat transfer is similar to the natural convection between two parallel plates, for which another correlation was used by $H$. $L u$ in [23]. More commonly, the general expression for engineering is given as follows,

$$
\mathrm{Nu}=\mathrm{C} \cdot[\mathrm{Gr} \cdot \mathrm{Pr}]^{p}
$$

where $C$ and $p$ are constants depending on whether the oil flow is laminar or turbulent. If it is laminar, $C$ is 0.59 and $p 0.25$ [9], [14], [21].

With the above formulas, a nonlinear thermal resistance can be obtained. However, the difficulties in determining the nonlinear thermal resistance involve the following aspects:

1) The characteristic length depends on the design parameters, meanwhile the winding structure (always in a zig-zag pattern) is not a smooth and complete cylinder and therefore needs further equivalent treatment;

2) In practice, the correlations are from off-the-shelf correlations that are not representative to the transformer cooling conditions, making errors inevitable.

3) The selection of the reference temperature $T_{\text {ref }}$ to determine the fluid properties and the temperature difference causing convective heat transfer also affect the nonlinear thermal resistance.

Therefore, we have to consider how to avoid the aforementioned drawbacks and uncertainties as much as possible. So, it is especially important to establish a set of differential equations that can describe the heat transfer reliably, which means the model can calculate temperature response accurately. Besides, the model should rely on fewer design parameters and fewer correlation coefficients.

2) Combined and Simplified Thermal Parameters Determination

For the heat transfer from the top of the winding to the adjacent oil by natural convection, the correlation for asymmetrically heated plates with vertical orientation and 


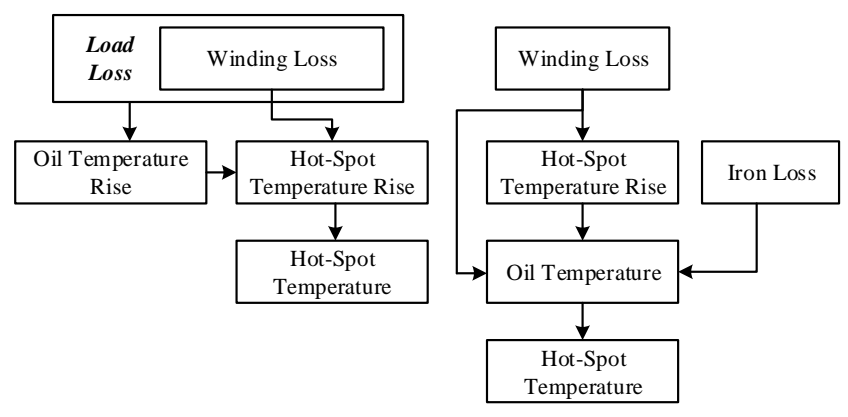

(a)

Fig. 3. Heat transfer process presented by (a) classical segmented model and (b) integrated model.

isoflux surface condition is [21]:

$$
N u_{\text {oil }}=C_{1} \cdot\left[S \cdot G r_{\text {oil }} \cdot P r_{\text {oil }} / L\right]^{p}
$$

Since the geometric parameters are fixed for one specific transformer, and the variation of viscosity with temperature is much higher than the variation of other oil parameters, by substituting (22), (23), and (25) into (20), we have

$$
h_{\text {oil }}=C_{1}^{\prime} \cdot\left[\frac{\Delta \theta}{\mu\left(\theta_{\text {ref }}\right)}\right]^{p}
$$

For $\alpha$ phase, $\theta_{\text {ref }}$ is the top-oil temperature $\theta_{\text {oil }}$ and $\Delta \theta=\Delta \theta_{\text {ahs }}$ - $\Delta \theta_{\text {oil }}$, by substituting (26) into (19), $\alpha$ phase hot-spot to top-oil thermal resistance $R_{t h-a h s-o i l}$ can be obtained:

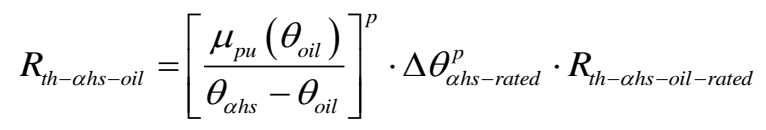

Similarly, the $\beta$ phase hot-spot to top-oil thermal resistance $R_{\text {th-Bhs-oil }}$ is

$$
R_{t h-\beta h s-o i l}=\left[\frac{\mu_{p u}\left(\theta_{\text {oil }}\right)}{\theta_{\beta h s}-\theta_{\text {oil }}}\right]^{p} \cdot \Delta \theta_{\beta h s-\text { rated }}^{p} \cdot R_{t h-\beta h s-\text { oil-rated }}
$$

where the coefficient $p$ should be 0.5 for (25), (26), (27) and (28), which is in accordance with the proposed value in [9] and its supporting articles.

The heat absorbed by oil is dissipated to air through the radiator/cooler by natural convection. It should be noted again that natural convection should be considered on the air side. The heat generated in the windings is dissipated through two coolants, namely oil in the tank and air outside of the tank. Hence, the governing equations for heat transfer involving oil (eq. 25 to eq. 28 ) and those involving air (eq. 29 to eq. 31 to be shown below) are treated separately since they describe different heat transfer processes.

For the heat transfer from the radiator inlet oil to the ambient, the natural convection can be described by the following empirical correlation in the same format as (24),

$$
N u_{\text {air }}=C_{2} \cdot\left[G r_{\text {air }} \cdot P r_{\text {air }}\right]^{q}
$$

Since the physical properties of the air do not change much with temperature (including viscosity), by substituting (22), (23) and (29) into (20), the following expression is obtained:

$$
h_{\text {air }}=C_{2}^{\prime} \cdot\left(\theta_{\text {oil }}-\theta_{\text {amb }}\right)^{q}
$$

So, the top-oil to the ambient thermal resistance $R_{\text {th-oil }}$ can be obtained according to (19) and (30) as,

$$
R_{\text {th-oil }}=\left[\frac{1}{\theta_{\text {oil }}-\theta_{\text {amb }}}\right]^{q} \cdot \Delta \theta_{\text {oil-rated }}^{q} \cdot R_{\text {th-oil-rated }}
$$

\section{Merging and Derivation of Governing Differential Equations}

In the thermal circuit model, the temperature drop has a linear relationship with the thermal resistance. However, the thermal resistance has a nonlinear relationship with its controlling parameters, such as power loss and liquid flow rate, etc.

$$
\begin{aligned}
& \Delta \theta=P \times R_{t h} \\
& \Delta \theta_{\text {ahs-rated }}=P_{\alpha-\text { rated }} \cdot R_{\text {th-ahs-oil-rated }} \\
& \Delta \theta_{\beta h s-\text { rated }}=P_{\beta-\text { rated }} \cdot R_{\text {th-Bhs-oil-rated }} \\
& \Delta \theta_{\text {oil-rated }}=\left(P_{\alpha-\text { rated }}+P_{\beta \text {-rated }}+P_{f e}\right) \cdot R_{\text {th-oil-rated }}
\end{aligned}
$$

Once the heat transfer accruing at thermal capacitance (absorbing or releasing heat) is finished, (33), (34) and (35) are satisfied, namely reaching the steady state.

With the basic information of the power transformer

$$
\begin{gathered}
P_{c u}=P_{\alpha}+P_{\beta} \\
r=\frac{P_{c u-\text { rated }}}{P_{f e}}
\end{gathered}
$$

and the fact that the thermal capacitance $C_{t h}$ barely changes with temperature as depicted in [9]. So, the thermal time constant only depends on the thermal resistance as shown in (38),

$$
\tau_{t h}=R_{t h} \cdot C_{t h}=R_{t h} \cdot C_{t h-r a t e d}
$$

So, the equation set (18) can be rewritten as (39) by considering (27), (28), (31), (33), (34), (35), (37) and (38).

As Fig. 3(b), the winding losses causes an average winding and oil temperature and both can contribute to the hot-spot temperature. The hot spot temperature is an output of the total system interaction within the winding. The so-called "integrated model" as Fig. 3(b) is more suitable for reflecting the interaction compared with the "segmented model" as Fig. 3(a).

\section{VERIFICATION}

\section{A. Parameters of the Traction Transformer}

As described in Introduction, traction transformers in TPSS work under electrical load with the following characteristics: 1) unbalanced; 2) overload. The above conditions are difficult to exist at the same time in power systems, so the traction transformer is the most suitable platform to research dynamic thermal performance under unbalanced loads.

The proposed model (39) was applied to estimate the hot-spot temperature of an energy-saving volume-core traction transformer, which was designed by Southwest Jiaotong 


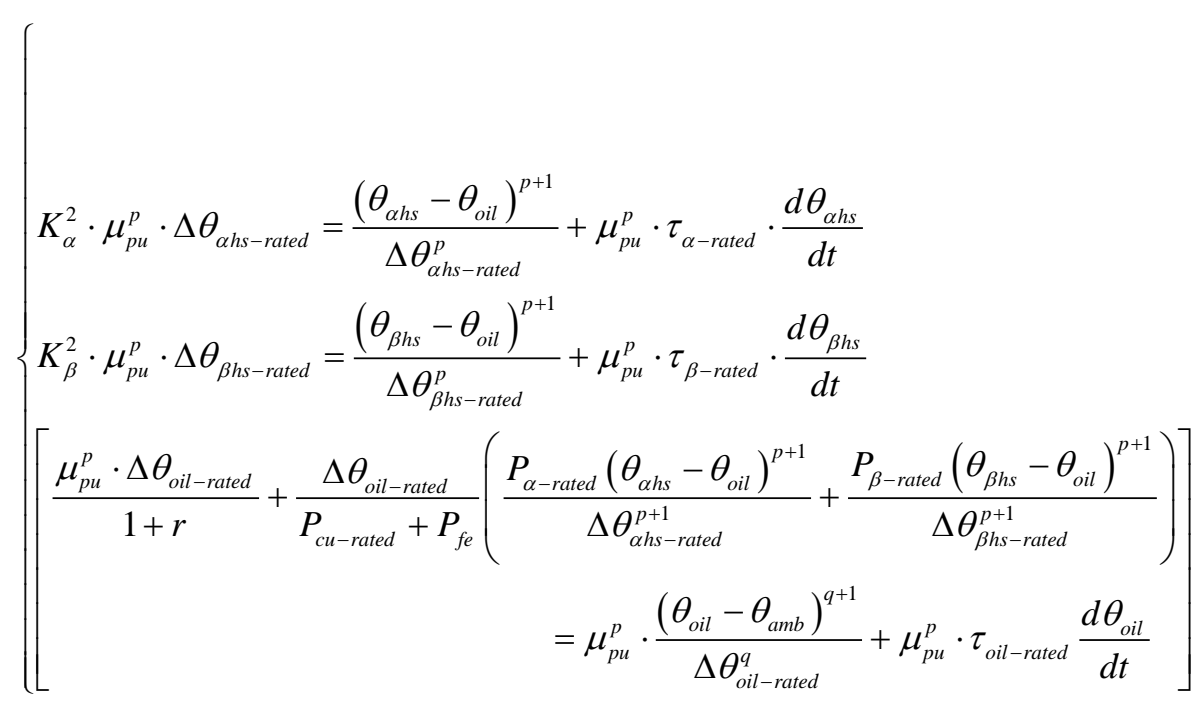

University and produced by Changzhou Pacific Electric Power Equipment (Group) Co., Ltd (CPEPE), as shown in Fig. 4. This transformer is a $(31.5+25)$ MVA unit with an ONAN cooling mode, where unequal capacity of two supply phases was designed to suit for the different traffic density at up-track and down-track. The detailed information of the transformer is provided in Table I. The verification for proposed model is also divided into two parts: the factory tests, and the field test.

The prototype must pass the type tests before a batch of transformers is manufactured from the factory. So before a traction transformer goes into operation, it must be subjected to an additional overload temperature rise test [24], [25] (as demanded by the railway standards), in which loading curve is shown in Fig. 5-a. During the tests, the two power supply phases were not powered with the same loads during some periods, simulating their unbalanced loading conditions. In the transformer assembly period as shown in Fig. 4a-b, in the upper part of the inside winding ( $\mathrm{T}$ winding), one fiber optic temperature sensor was embedded into the preset slot in the spacer between disc 3 and disc 4 named from the top. The measurement range, accuracy and resolution of the fiber optic sensor are $-40 \sim+260^{\circ} \mathrm{C}, \pm 1 \mathrm{~K}$ and $0.1 \mathrm{~K}$ respectively. With the
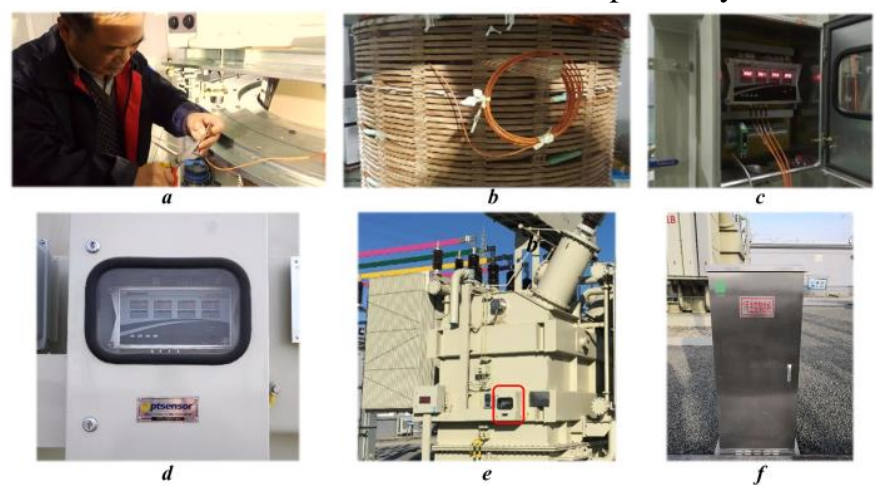

Fig. 4. Intelligent traction transformer monitoring system: (a) installation of fiber optic probes; (b) installed probes inside winding with its external wire; (c) probes connected to temperature monitoring system; (d) temperature monitoring system at the external wall of tank; (e) operating traction transformers; (f) intelligent monitoring and control cabinet including temperature, DGA, moisture in oil. intelligent monitoring and control system, the data including temperature, load current, were recorded from 1\# traction transformer of Pingquan traction substation in Beijing-Shenyang High-speed Railway.

\section{B. Verification with Temperature Rise Tests in Factory}

The loading profile, ambient temperature during the temperature rise test, and estimated hot-spot temperatures are presented in Fig. 5. In Fig. 5 and Fig. 6, $\alpha$ calcu. and $\beta$ calcu. represent calculated value by (39) with original $p, q$ constant in Table I for $\alpha$ and $\beta$ phases respectively; $\alpha$ mea. and $\beta$ mea. represent measured value for $\alpha$ and $\beta$ phases respectively.

It can be seen from Fig. 5 that the two phases are alternately subjected to overload, and the overload of one phase will cause the temperature rise sharply. However, since the two phases share the same reference oil temperature in space, the temperature rise of the overload phase will also indirectly affects the temperature of the other phase. The calculated

TABLE I

PARAMETER OF THE TRACTION TRANSFORMER AND THE INPUT DATA OF THERMAL MODEL

\begin{tabular}{|c|c|c|}
\hline \multirow{2}{*}{ Quantity } & \multicolumn{2}{|c|}{ Traction Transformer } \\
\hline & $\alpha$ phase & $\beta$ phase \\
\hline Rated Power (MVA) & 31.5 & 25 \\
\hline Rated Voltage $(\mathrm{kV})$ & $220 / 27.5 / 27.5$ & $220 / 27.5 / 27.5$ \\
\hline Rated Load Loss (kW) & 68.44 & 59.72 \\
\hline Iron Loss $(\mathrm{kW})$ & \multicolumn{2}{|c|}{32.34} \\
\hline$r$ & \multicolumn{2}{|c|}{3.96} \\
\hline$D C$ Resistance $(\Omega)$ & $1.855 / 0.017 / 0.020$ & $2.610 / 0.024 / 0.027$ \\
\hline Rated Current (A) & $143.2 / 572.8 / 572.8$ & $113.6 / 454.4 / 454.4$ \\
\hline$\eta$ & 0.364 & 0.351 \\
\hline$\Delta \theta_{\text {oil-rated }}(\mathrm{K})$ & \multicolumn{2}{|c|}{26} \\
\hline$\theta_{\text {oil-rated }}(\mathrm{K})$ & \multicolumn{2}{|c|}{48} \\
\hline$\Delta \theta_{\text {hs-rated }}(\mathrm{K})$ & $\Delta \theta_{\text {ahs-rated }}: 19$ & $\Delta \theta_{\beta h s-\text { rated }}: 16$ \\
\hline$\tau_{w-\text { rated }}(\min )$ & $\tau_{\alpha-\text { rated }}: 10$ & $\tau_{\beta-\text { rated }}: 12$ \\
\hline$\tau_{\text {oil-rated }}(\mathrm{min})$ & \multicolumn{2}{|c|}{$\tau_{\text {oil-rated }}: 110$} \\
\hline$p$ & \multicolumn{2}{|c|}{0.25} \\
\hline$q$ & \multicolumn{2}{|c|}{0.25} \\
\hline Cooling Type & \multicolumn{2}{|c|}{ ONAN } \\
\hline Oil Type & \multicolumn{2}{|c|}{ Karamay (25\#) } \\
\hline
\end{tabular}

"Slash (/) denotes the parameters for HV/T/F windings respectively. 

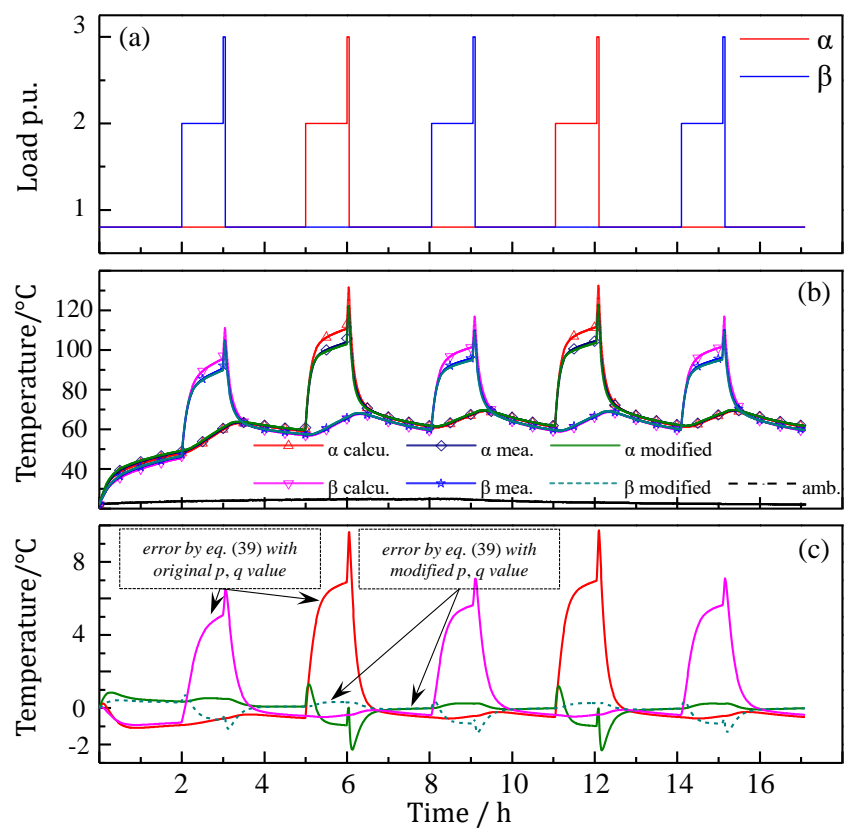

Fig. 5. Comparison results: (a) loading profile; (b) results comparisons between (39) with original $p, q$ value and (39) with modified $p, q$ value for hot-spot temperature; (c) error produced by different $p, q$ value.

temperature of the model (39) with original $p, q$ constant in Table I is basically consistent with the measured value, but under multiple overloads (2.0 p.u. or more), the error will become larger, since the uncertainty of the parameter is amplified under overload.

In view of the above model input parameters, the constants $p$, $q$ are only two empirical coefficients. The two coefficients $p$ and $q$ are changed in the range from 0 to 0.5 , with a step size of 0.01 . All combinations of $p$ and $q$ in the above range were tried to find the smallest error. The error is the smallest when $p$ is 0.43 and $q$ is 0.24 which are used for $\alpha$ modified and $\beta$ modified. So $\alpha$ modified and $\beta$ modified represent calculated value by (39) with optimized $p, q$ constants for $\alpha$ and $\beta$ phases respectively. With the optimized $p, q$ values, the model of (39) yield error reduction from $9.7 \mathrm{~K}$ to $2.7 \mathrm{~K}$, as shown in Fig. 5 (c).

\section{Verification with Field Operation Data}

The loading current $I_{\alpha T}, I_{\alpha F}, I_{\beta T}, I_{\beta T}$, ambient temperature and measured temperature during a 24-hour operation are presented in Fig. 6.

The high-speed rail is not running from 0:00 to 6:00 in the morning when the equipment is going through maintenance. The load current is periodic, because the load current is related to the scheduling operation by EMUs. Therefore, the 24-hour load current is representative. For the proposed model, the initial data entered are also the monitoring data at 0:00. It is noted that $\alpha$ modified and $\beta$ modified still use $p$ being 0.43 and $q$ 0.24 since the traction transformer in field and the one in the factory test belong to the same batch.

\section{Discussion for the Two Verification Cases}

In the factory temperature rise test shown as Fig. 5, due to the short-time overload based on higher benchmark load (0.8 p.u.),

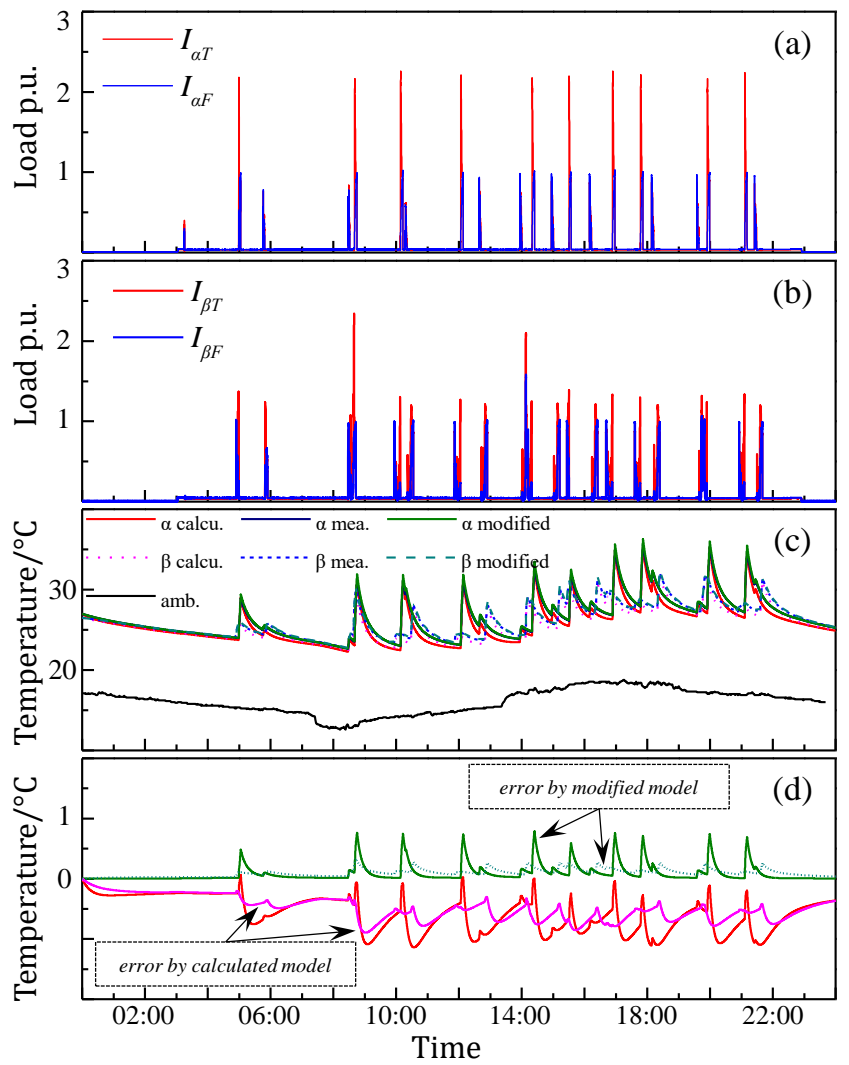

Fig. 6. Comparison results: (a) $\alpha$ phase loading profile; (b) $\beta$ phase loading profile; (c) hot-spot temperature of the $27.5-\mathrm{kV}$ winding in the $(31.5+25)$ MVA ONAN traction transformer; (d) error produced by different dynamic thermal model.

there exist more significant differences between measurements and modeled results during the overload period. Equation (39) with optimized $p, q$ values reduces the error by $7.5 \mathrm{~K}$. It is significant since insulation paper thermal ageing is doubled for every increase of 6-7 K. Of course, this loading scenario is extreme and rare, but it may occur to some traction transformers served in hub-substations. So, in the future, the hot-spot temperature monitoring is needed for newly commissioned traction transformers served in hub-substations.

It can be seen from Fig. 6 that the load density is pretty low so that the maximum hot-spot temperature rise over ambient is less than $20 \mathrm{~K}$. Compared with the measurement data, the maximum errors from model (39) with different parameter combinations are all within $1 \mathrm{~K}$. In more intensive loading scenarios, the model with parameter optimization is expected to show superiority as demonstrated in the factory test case.

In general, it can be expected for the following

1) The model is effective and can capture this unbalanced temperature rise feature.

2) The effect of parameter calibration will be amplified as the short-term overload and the average load increase.

3) The calibrated parameters of one unit are suitable for others in the same batch of transformers served in a residential area or a railway line. 


\section{CONCLUSION}

In order to explore the dynamic thermal performance of the transformer under unbalanced load (current). This paper established a lumped thermal circuit model. The nonlinear thermal resistance was modeled and simplified based on heat transfer principles. The following conclusions were drawn:

1) For the unbalanced heat generation caused by the unbalanced load of the transformer, the relationship between the thermal circuit and the heat transfer process was established.

2) When deriving the differential equations based on the thermal circuit, the parameters were associated with the temperature rise test results to reduce the dependence on the design parameters, the use of the correlation equations and the number of coefficients.

3) For the traction transformers in non-hub substations, the maximum hot-spot temperature rise is about $20 \mathrm{~K}$ because the loading density is far below the rated thermal capacity despite of many pulsed overloading scenarios.

It should be mentioned that this method is expected to be valid for other practical cases with different thermal designs or different cooling liquids used, although the parameters need to be optimized with the same methodology. For instance, alternative liquids (e.g. synthetic and natural esters which have different thermal properties) are increasingly being used in traction transformers.

From the perspective of temperature rise and thermal ageing, the questions of how to design new substations economically and how to utilize the remaining capacity of existing substations are to be further studied.

\section{REFERENCES}

[1] J. I. Aizpurua, S. D. J. McArthur, B. G. Stewart, B. Lambert, J. G. Cross and V. M. Catterson, "Adaptive power transformer lifetime predictions through machine learning and uncertainty modeling in nuclear power plants," IEEE Trans. Ind. Electron., vol. 66, no. 6, pp. 4726-4737, Jun. 2019.

[2] M. Andresen, V. Raveendran, G. Buticchi, and M. Liserre, "Lifetime-based power routing in parallel converters for smart transformer application," IEEE Trans. Ind. Electron., vol. 65, no. 2, pp. 1675-1684, Feb. 2018.

[3] Z. Liu and K. Hu, "A model-based diagnosis system for a traction power supply system," IEEE Trans. on Industrial Informatics, vol. 13, no. 6, pp. 2834-2843, Dec. 2017.

[4] D. Villacci, G. Bontempi, A. Vaccaro, and M. Birattari, "The role of learning methods in the dynamic assessment of power components loading capability," IEEE Trans. Ind. Electron., vol. 52, no. 1, pp. 280-290, Feb. 2005.

[5] D. L. Alvarez, S. R. Rivera and E. E. Mombello, "Transformer thermal capacity estimation and prediction using dynamic rating monitoring," IEEE Trans. Power Del., vol. 34, no. 4, pp. 1695-1705, Aug. 2019.

[6] L. Zhou, J. Wang, L. Wang, S. Yuan, L. Huang, D. Wang, and L. Guo, "A method for hot-spot temperature prediction and thermal capacity estimation for traction transformers in high-speed railway based on genetic programming," IEEE Trans. Transport. Electrific., vol. 5, no. 4, pp. 1319-1328, Dec. 2019.

[7] L. Zhou, D. Wang, L. Guo, L. Wang, J. Jiang, and W. Liao, "FDS analysis for multilayer insulation paper with different aging status in traction transformer of high-speed railway," IEEE Trans. Dielectr. Electr. Insul., vol. 24, no. 5, pp. 3236-3244, Oct. 2017

[8] A. Y. Arabul and I. Senol, "Development of a hot-spot temperature calculation method for the loss of life estimation of an ONAN distribution transformer," Electr. Eng., vol. 100, pp. 1651-1659, Sep. 2018.
[9] D. Susa and M. Lehtonen, "Dynamic thermal modeling of power transformers: further development - part I," IEEE Trans. Power Del., vol. 21, no. 4, pp. 1961-1970, Oct. 2006.

[10] H. Hu, P. Pan, Y. Song and Z. He, "A novel controlled frequency band impedance measurement approach for single-phase railway traction power system," IEEE Trans. Ind. Electron., vol. 67, no. 1, pp. 244-253, Jan. 2020

[11] W. Tang, Q. Wu, and Z. J. Richardson, "A simplified transformer thermal model based on thermal-electric analogy," IEEE Trans. Power Del., vol. 19, no. 3, pp. 1112-1119, Jul. 2004.

[12] M. Djamali, S. Tenbohlen, E. Junge, and M. Konermann, "Real-time evaluation of the dynamic loading capability of indoor distribution transformers," IEEE Trans. Power Del., vol. 33, no. 3, pp. 1134-1142, Jun. 2018

[13] L. Wang, L. Zhou, S. Yuan, J. Wang, H. Tang, and L. Guo, "Improved dynamic thermal model with pre-physical modelling for transformers in ONAN cooling mode," IEEE Trans. Power Del., vol. 34, no. 4, pp. 1442-1450, Aug. 2019.

[14] J. Sandraz, F. de León and J. Cultrera, "Validated transient heat-transfer model for underground transformer in rectangular vault," IEEE Trans. Power Del., vol. 28, no. 3, pp. 1770-1778, Jul. 2013.

[15] M. Z. Degefa, R. J. Millar, M. Lehtonen, and P. Hyvonen, "Dynamic thermal modeling of MV/LV prefabricated substations," IEEE Trans. Power Del., vol. 29, no. 2, pp. 786-793, Apr. 2014.

[16] Y. Cui, H. Ma, T. Saha, C. Ekanayake and D. Martin, "Moisture-dependent thermal modelling of power transformer," IEEE Trans. Power Del., vol. 31, no. 5, pp. 2140-2150, Oct. 2016.

[17] A. Najafi and I. Iskender, "An improved thermal model for distribution transformer under unbalanced voltage conditions," Int. J. Therm. Sci., vol. 104, pp. 373-385, 2016

[18] K. Karsai, D. Kerenyi, L. Kiss, Large Power Transformers, New York: Elsevier Company, 1987.

[19] R. M. Del Vecchio, B. Poulin, P. T. Feghali, D.M. Shah and R. Ahuja, Transformer Design Principles - With Application to Core - Form Power Transformer. $2^{\text {nd }}$ ed. Boca Raton: CRC Press, 2010.

[20] J. R. Welty, G.L. Rorrer and D.G. Foster, Fundamentals of Momentum, Heat and Mass Transfer, $6^{\text {th }}$ edition. New York: John Wiley and Sons Inc., 2013.

[21] F. P. Incropera, D. P. DeWitt, Theodore L. Bergman and Adrienne S. Lavine, Fundamentals of Heat and Mass Transfer, $6^{\text {th }}$ edition. New York: John Wiley and Sons Inc., 2007.

[22] S. W. Churchill and H. H. S. Chu, "Correlating equations for laminar and turbulent free convection from a vertical plate," Int. J. Heat Mass Transf., vol. 18, no. 9, pp. 1323-1329, 1975.

[23] H. Lu, A. Borbuev, S. Jazebi, T. Hong, and F. de León, "Smart load management of distribution-class toroidal transformers using a dynamic thermal model," IET Gener. Transm. Distrib., vol. 12, no. 1, pp. 142-149, Jan. 2018.

[24] Power Transformers-Part 7: Loading Guide for Oil-Immersed Power Transformers, IEC 60076-7, 2005.

[25] IEEE Recommended Practice for Performing Temperature Rise Tests on Oil-Immersed Power Transformers at Loads Beyond Nameplate Ratings, IEEE Standard C57.119, 2001.

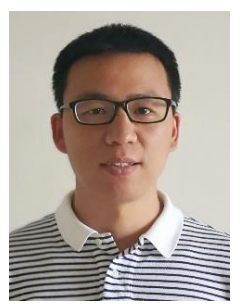

Lijun Zhou (M'10) was born in 1978, in Hangzhou, China. He received the B.Sc., M.Sc. and Ph.D. degrees in electrical engineering, respectively in 2001, 2004 and 2007 from Southwest Jiaotong University, Chengdu, where he is a professor of electrical engineering.

His current research interests mainly include condition monitoring, fault diagnosis and insulation life-span evaluation for electrical equipment.

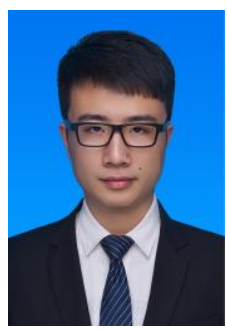

Lujia Wang (S'18-M'20) received the B.Sc. and Ph.D. degrees in electrical engineering, respectively in 2015 and 2020, from Southwest Jiaotong University, Chengdu, China.

He was a joint Ph.D. student with the School of Electrical and Electronic Engineering, The University of Manchester, Manchester, U.K. Since 2020, he has been a lecturer in the School of 
Electrical and Power Engineering, China University of Mining and Technology, Xuzhou, China. His current research interests mainly include transformer thermal modeling and fault diagnosis.

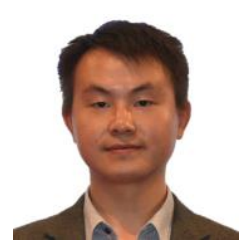

Xiang Zhang received the B.Eng. degree in Electrical and Electronic Engineering (2012) from Xi'an Jiaotong University in China, and $\mathrm{PhD}$ degree in Electrical Engineering (2017) from The University of Manchester in the UK. Currently he is a lecturer in the Department of Engineering at The

Manchester Metropolitan University. His research
interests are on thermal management of power transformers, motors and EV battery packs.

transformers, motors and EV ba

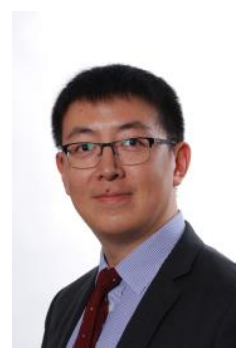

Qiang Liu (S'08-M'12-SM'18) obtained the B.Eng. degree in electrical engineering (2005) and the M.Eng. degree in high voltage and electrical insulation (2008) from Xi'an Jiaotong University in China, and the Ph.D. degree in electrical power engineering (2011) from The University of Manchester in the UK. Currently he is a Reader of Power System Plant in the Department of Electrical and Electronic Engineering at The University of Manchester.

His research interests focus on dielectric fluids and their applications in high voltage power equipment including characterization of advanced dielectric liquids (esters and gas-to-liquids), discharge and breakdown mechanisms of dielectric liquids, novel ageing indicators of liquid-solid insulation system, dynamic thermal rating and asset management of power transformers.

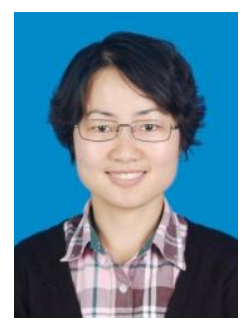

Lei Guo received the B.Sc., M.Sc. and Ph.D. degrees in electrical engineering, respectively in 2002, 2005 and 2012, from Southwest Jiaotong University, Chengdu, where she is an associate professor from 2016. Her current research interests mainly include traction power supply analysis and on-line anti-icing for catenary

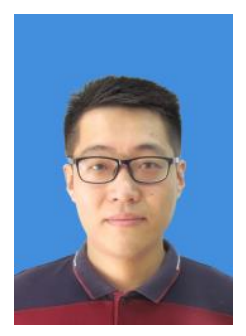

Dongyang Wang (M'19) received the B.Sc. and Ph.D. degrees in electrical engineering, respectively in 2012 and 2018 from Southwest Jiaotong University, Chengdu.

$\mathrm{He}$ worked as a Chief Designer in CRRC Qingdao Sifang Co., Ltd. He was a post-doctoral fellow in University of Macau. He is engaged in research on prognostic health monitoring (PHM) and fault diagnosis for electromechanical equipment. 